\title{
Is there a partisan bias in the perception of the state of the economy? A comparative investigation of European countries, 2002-20I 6
}

International Political Science Review

(C) The Author(s) 2020 Article reuse guidelines: sagepub.com/journals-permissions DOI: I0.II77/0I925I2I209|5907 journals.sagepub.com/home/ips

\section{Martin Okolikj iD and Marc Hooghe}

KU Leuven, Belgium

\begin{abstract}
The literature on economic voting starts from the assumptions that citizens have a sufficiently high level of knowledge about their country's economic situation, and that they vote according to their perception of the state of the economy. However, these assumptions have been challenged as economic perceptions could be plagued by partisan bias. We use the comparative dataset of the European Social Survey to investigate partisan bias in the perception of economic performance. Firstly, we observe that the economic perceptions of both supporters and opponents of governing parties are strongly related to real-life economic indicators such as gross domestic product growth and unemployment levels. Secondly, we find that shifts in economic performance (growth and unemployment) are strongly associated with similar changes in economic perceptions among both supporters of governing parties and opposition parties. There is, however, a significant but limited partisan bias in economic perceptions in countries with high levels of unemployment.
\end{abstract}

\section{Keywords}

Economic voting theory, economic perceptions, partisanship, endogeneity, European Social Survey

\section{Introduction}

Using European Social Survey (ESS) data, we test the association between economic perceptions and real economic indicators among voters for the incumbent government as well as for the opposition, in order to investigate whether economic perceptions are biased by partisan affiliations.

Perceptions about the state of the national economy play a key role when investigating retrospective economic voting behaviour (Anderson et al., 2004; Lewis-Beck and Nadeau, 2011). The basic assumption is that voters will punish incumbents if they think the economy is doing badly, 
while they will reward incumbents when they perceive things are going well. Nevertheless, some scholars have argued that perceptions about the state of the economy are inherently problematic (Evans and Andersen, 2006; Van der Brug et al., 2007). As most voters will make little effort to seek correct information about the specific impact of policies, their subjective assessment of the governing parties' performance will deviate, at least partially, from real-life economic indicators (Zaller, 1992). Inevitably, this means that there will not be a perfect correlation between macroeconomic indicators and economic perceptions among the population (Paldam and Nannestad, 2000). The absence of an accurate view, however, would be especially troublesome if there is a systematic bias among citizens. If citizens base their judgement about the performance of the economy on their own party preferences rather than on real economic indicators or on their experienced economic reality, the entire alleged relationship between economic perceptions as a predictor of vote choice becomes implausible. If partisanship would determine one's perception of the state of the country, rather than the other way around, this would mean that the entire literature on economic conditions determining electoral choices becomes endogenous and therefore meaningless (Kramer, 1971; Wilcox and Wlezien, 1993).

In response to the criticism that perceptions are biased by partisanship, ${ }^{1}$ proponents of economic voting theory have claimed that the observed error is largely random (Stevenson and Dutch, 2013). Indeed, if the error is mostly random, perceptions about the economy can still be used in order to predict voting behaviour. One does not expect that voters have a profound knowledge of economic indicators, but as long as they have a more or less accurate perception of how the economy is doing, this might be sufficient to drive economic voting (Sanders, 2000). By itself, there is nothing wrong with the fact that government supporters are slightly more positive about the economy than opposition supporters. As long as both groups can recognize a period of crisis or prosperity, the basic assumptions of economic voting theory still hold. But when economic growth or unemployment are systematically perceived differently by adherents of opposition or government parties, it would not make sense to use economic perceptions to explain vote choice (Conover et al., 1986).

The occurrence of partisan bias would imply that there is a systematic difference between perceptions of economic performance and objective economic indicators. Therefore, in this article we will investigate the difference between perceptions and real-life indicators. This is a strict test, as merely showing there is a difference depending on one's ideological preference might be informative but is not sufficient to imply that there is a systematic bias. Only if the noise resulting from the bias significantly corrupts the original signal is it clear that we can no longer use this kind of information in a reliable manner. In other words, if supporters of the incumbent governing party observe improvements in the economy while they ignore economic contractions, then it is clear that perceptions are endogenous. The same is true if their counterparts, who support an opposition party, do not react to positive economic changes. Then we could claim that economic perceptions are indeed rooted in partisan bias. However, if both sides would similarly detect improvements or declines in economic performance, this would offer evidence for an independent effect of economic perceptions regardless of partisan identification.

Our analysis is based on the full dataset of all eight waves of the ESS. ${ }^{2}$ This is a high-quality and representative dataset, and the availability of data for the period 2002-2016 provides more variation in our data. This is an important consideration, since we want to compare perceptions with real-life data, which, self-evidently, only makes sense if there is sufficient variation in this regard. During the first years of this period, European countries had a rather prosperous economy, which was interrupted by the economic crisis of 2008. In more recent years, we have witnessed a gradual economic recovery, with unemployment levels reverting to pre-crisis levels. Respondents 
participating in the various waves thus experienced both prosperous periods and periods of acute economic crisis, and this variation allows us to assess the reliability of their country's economic condition.

In this article, we first review the literature on the theoretical status of retrospective economic assessments in the framework of economic voting. Subsequently, we ascertain to what extent these perceptions accurately reflect economic indicators, before investigating whether partisan preferences introduce a systematic bias in this assessment. We conclude with some observations on what these comparative European findings imply for the validity of the theory on economic voting.

\section{Literature and theory}

Empirical studies have shown that there is a correlation between perceptions of the economy and voting behaviour. Citizens tend to punish the incumbent parties and candidates when the national economy is doing badly. This implies that in some way or another, politicians are being held accountable for the state of the economy (Lewis-Beck and Stegmaier, 2000). Despite the central role of economic evaluations in the vote-choice process, we know remarkably little about the kind of information this perception is based on. If gross domestic product (GDP) growth and levels of unemployment help to determine voter behaviour, it is important, first that voters are aware of these conditions, and second that they attribute to governing parties responsibility for the state of the economy. Whether this is indeed the causal mechanism for economic voting, however, has been heavily disputed.

One of the strongest critiques of economic voting theory is based on the argument that economic perceptions are based, to a large extent, on political preferences: supporters of the government have a more optimistic view of the state of the economy than those who vote for an opposition party (Anderson, 2007). Some empirical research indeed suggests that economic perceptions can be structurally different, depending on the political preferences of the respondent, thus invalidating the use of economic perception measures (Van der Brug et al., 2007). Evans and Andersen (2006) also show that economic perceptions are to some degree influenced by party identity. Duch et al. (2000) used American national survey data and found evidence for a strong partisan bias in the evaluation of the economy (Evans and Pickup, 2010).

However, there is also disparity in the economic voting literature regarding endogeneity. De Vries et al. (2018), for example, show that government and opposition supporters both have realistic views of the economy. They conclude that even though partisanship influences the assessment of the economy, both sides respond in the same way to economic changes. In response to Duch et al. (2000), Lewis-Beck and Nadeau (2011) found strong evidence of an economic vote in the 2008 US presidential elections. Similar evidence of economic voting has been shown in different European countries (Lewis-Beck et al., 2013; Nadeau et al., 2013; Lewis-Beck et al., 2008). The culmination of this debate is evident in Evans and Chzhen's (2016a, 2016b) critique of the valence model and in Whiteley et al.'s (2016) subsequent response.

In our study we test the effect of real economic indicators on economic perceptions, distinguishing those who support opposition parties from those who support governing parties. We include a large sample of 30 countries which allows us to test this relationship in different political settings, providing us with a variety of electoral systems (majoritarian, proportional representation (PR) and mixed) and party governing structures (coalition governments and single party governments), as well as different social and cultural backgrounds (Western European democracies, third-wave democracies, and post-communist democracies). 
In this line of research, Parker-Stephen (2013) has investigated the relationship between real economic performance and simultaneous positive and negative perceptions of the economy by different groups of partisans in the US. He concluded that, when it seems equally clear to everyone how the economy is doing, disagreements are larger in normal times and only marginal in extremely bad or good times, (Parker-Stephen 2013). De Vries et al. (2018: 121), using observational and experimental data, found that British voters, regardless of partisanship, updated their economic perceptions to respond to changes in the real economy. This approach to investigating the determinants of economic perceptions has been implemented to some extent by Nadeau et al. (2013), in order to examine the relationship between economic perceptions and real economic indicators in 10 Western European democracies. However, no distinction was made between opposition and governing party supporters, and that is a step we will take in this paper (Nadeau et al., 2013). We also follow Whiteley and Kölln (2019) who use a similar modelling approach, yet do so from a very different perspective, as they focus on types of partisanship and their effect on accountability.

By broadening the set of observations across time and across societies, we introduce variation in the macro-economic conditions, thereby enabling us to assess whether respondents' assessment of the economy is in line with the real economic indicators. In this regard, the literature is rather optimistic. Voters may not have full knowledge of the macro-economic indicators of their country (Paldam and Nannestad, 2000), but they do seem to be quite knowledgeable about whether the economy is prosperous or not (Okolikj and Quinlan, 2016). As Sanders (2000: 276) noted, voters do have a reasonably well-founded idea about the state of the economy: "voters do not need to know precise "economic facts" in order to make reasonably well-informed judgements about the state of the economy'. Indeed, perceptions might not be fully accurate as specific circumstances have an effect on economic perceptions. These limitations, however, do not prevent voters from having at least a proximal impression of the state of the economy (Borre, 1997; Healy and Lenz, 2017).

The relationship between economic perceptions and real economic indicators is a precondition for our later test of the relationship between partisanship and economic perceptions. If voters are not able to adequately judge economic changes, there is an irrefutable problem in the way economic perceptions are measured. Thus, it is crucial to investigate the correlation between economic perceptions and real economic performance, prior to introducing partisanship into the equation. Therefore, our first inquiry investigates the premises for our later hypothesis and looks into the association between economic perceptions and real economy indicators:

\section{H1: Economic perceptions are positively associated with GDP growth and negatively associ- ated with levels of unemployment.}

The crucial question, however, remains: even if perceptions about the economy follow real economic performance, the endogeneity claim expects that this economic effect will be different based on the party one supports. This assumes that voters for the incumbent government will be more optimistic about the economy, even in times of stagnation and recession, compared to respondents who voted for an opposition party. If this argument is valid, citizens would not have an accurate view of the state of their country's economy, and their perception would merely reflect their partisan preference. It would also imply that governments are not actually held accountable for the consequences of their economic policies (Anderson, 2007). Therefore, it is crucial to investigate whether both opposition and incumbent supporters have an adequate view of their country's economy. If incumbent supporters perceive economic decline while in reality 
the economy flourishes, this would be a strong indication for the claim that economic perceptions are a product of partisanship.

Therefore, our second and third hypotheses investigate this link between respondents who voted for the governing or opposition party and their perceptions of the economy. We look at both the starting point (intercept) and the changes (slope):

H2: Voters for a governing party perceive real economic indicators more positively compared to those who voted for an opposition party.

H3: Voters for a governing party perceive changes in real economic indicators more positively compared to those who voted for an opposition party.

\section{Data and operationalization}

In our analysis, we use the ESS as our main dataset for individual-level observations. The advantage of the ESS is not just that it offers high-quality representative population data, but also that it covers a wide range of European democracies. This allows us to move beyond single-country case studies, while it also broadens our observations to a considerable number of countries outside the usual studies of the US or the UK. Our ESS sample includes all the surveys from the ESS round 1, conducted in 2002, up to the latest, ESS round 8, which was conducted in 2016. The total number of countries in our data is 30 with 339,551 individual observations. The ESS data include the same questions across all rounds of surveys, making it ideal for our cross-time cross-sectional analysis.

Our main dependent variable is satisfaction with the state of the economy in the country, which is measured by the question: 'On the whole how satisfied are you with the present state of the economy in [country]'. The scale ranges from 0 to 10 , with 0 meaning extremely dissatisfied and 10 extremely satisfied. The question clearly refers to a classic sociotropic evaluation of the economy (Borre, 1997), where respondents evaluate overall economic performance rather than an individual egotropic evaluation of the economy (the so-called pocketbook question).

We use this sociotropic evaluation in our modelling because:

1. We investigate voters' ability to understand real economic indicators.

2. The endogeneity critiques focus on sociotropic economic perceptions and partisanship.

3. Sociotropic evaluations are better predictors of vote choice and therefore preferred in the economic voting literature (Lewis-Beck and Stegmaier, 2013);

4. The ESS does not include a classic pocketbook questions and if we would like to include this in our analysis we would have to rely on proxy variables such as income.

To assess the degree to which economic perceptions are related to real-life trends, we rely on aggregate economic indicators. We use two country-level economic measures from the World Bank: GDP growth and levels of unemployment. In the literature on economic voting, both indicators are being used rather interchangeably (Nadeau and Lewis-Beck, 2001). While the growth of GDP offers the most comprehensive operationalization of economic performance, it could also be argued that this is a rather abstract notion and it can be expected that most citizens are not necessarily aware of its effects on their daily life. Rising unemployment, on the other hand, is much easier to observe, as those who are not unemployed themselves may have relatives or neighbours who have lost their jobs. Previous research indeed suggests that voters are better informed about unemployment levels than about other economic indicators (Paldam and Nannestad, 2000). From 
an experience perspective, it therefore seems more straightforward to expect citizens to base their economic evaluation on what they can observe with regard to unemployment in their own community (Ansolabehere et al., 2014). As we do not have a firm theoretical position to prefer GDP growth or unemployment levels, ${ }^{3}$ we include both in our models. It has to be observed that the correlation between the two indicators is self-evidently negative, but all in all rather limited (-0.09). This means that both indicators can be included simultaneously without a danger of introducing multicollinearity.

In order to assess the political preference of the respondent, we rely on a rather pragmatic approach. The literature on economic voting assumes that while there might be a general preference for governing parties, ultimately it is the party of the prime minister that is being held accountable for the state of the economy (Dassonneville and Hooghe, 2012; Hernández and Kriesi, 2016; Nadeau et al., 2013). As there are solid arguments for both operationalizations, both of them are used in our analysis. More specifically, we use two binary vote choice variables: first, a vote for the governing party (compared to a vote for an opposition party), and second, a vote for the prime ministerial party (compared to all other parties). The governing party variable is coded 1 if respondents have reported a vote for one of the governing parties, while those who have cast a vote for an opposition party are coded 0 . Similarly, we use a vote for the prime ministerial party (coded 1) and all the other parties (coded 0). ${ }^{4}$ Both variables are based on two datasets from the Party Systems and Governments Observatory (PSGo) and from the Parliament and Government research group (ParlGov). All parties that have held a ministerial position during the governing period are included as governing parties.

In order to test our second and third hypotheses, we run interaction terms between the two aggregate economy variables (growth and unemployment level) and our two vote-choice variables, vote for the governing party and vote for the prime ministerial party. By using an interaction term, we can detect possible differences in economic perceptions in comparison to the real economic performance among those respondents who have voted for a governing party or the prime ministerial party and those whose vote was for one of the opposition parties. The hypothesis in both cases is clear: if there is a systematic bias in economic perceptions, we should observe a significant interaction effect.

Since the main goal of this paper is to investigate partisanship bias in economic perceptions, it is important to control for political variables that might affect this relation. The ideal model would investigate economic perceptions unaffected by other factors, as much as that is possible. Therefore, in order to isolate the economic perceptions, we keep political factors constant in the equation. If after controlling for political variables we still find that economic perceptions mimic partisanship affiliation, this would be a strong indication for endogeneity. To control for the political preferences of the respondents, we use two standard political measures commonly employed in the economic voting literature, party identification and the ideological views of the respondent. For ideology, we use a standard left-right self-placement question. For party identification we use a binary variable, where respondents are asked if they are close to a political party (coded 1) or not (coded 0$)$.

In addition to controlling for political variables, we use standard demographic characteristics of the respondents, such as age, education and gender. ${ }^{5}$ We also include aggregate country level covariates to control for the electoral system in the countries of our sample, where we use the level of disproportionality of the electoral system, effective number of parties at the electoral level and effective number of parties at the parliamentary level for each country in our sample. ${ }^{6}$ For this we rely on the Gallagher dataset. Our assumption here is that a low number of effective political parties may be more easily associated with polarization between government and opposition, and this could lead to a stronger bias. A broader range of competing political parties, on the other hand, 
should reduce partisan bias (Hooghe and Oser, 2017). This expectation is also in line with the clarity of political responsibility hypothesis (Powel and Whitten, 1993), where two party systems are expected to have a clearer pattern of responsibility.

The clustered nature of our data requires a multilevel approach. When observations are nested within the sample, they violate the assumption of independence, increasing the probability of Type-I error (Gelman and Hill, 2006). Multilevel modelling takes into consideration this nested nature of our sample. We have 2 levels of analysis in our models, with 201,126 respondents nested in 30 countries and 8 survey years, leading to 178 country year random intercepts. ${ }^{7}$ For robustness, we ran the same analysis from Table 2 using different model specifications, such as country fixed effects and OLS (Appendices 5, 8, 9 and 10 available in the Supplemental material online). ${ }^{8,9}$

\section{Empirical findings}

\section{Descriptive analysis}

We start our analysis by looking at the distribution of satisfaction with the economy and the corresponding real economic performance among our sample countries, in order to ascertain whether economic perceptions follow a similar path as real economic performance. First, we observe that the average score on satisfaction with the economy varies rather strongly across the various waves. During the period 2002-2006 the perception scores tend to be close to 5, but they take a steep drop to 4 from 2008 on. In the last two waves of the ESS, however, we observe that economic evaluations return to the previous level of satisfaction with an average score of around 5. In Figure 1, we notice that the drop in the reported satisfaction with the economy is similar to and simultaneous with the drop in GDP growth that occurs between 2008 and 2012. The upward economic trend since 2014 reflects itself in higher levels of GDP growth and declining levels of unemployment and is equally associated with a rise in the average level of satisfaction with the economy among respondents in the last two waves of ESS (Figure 1).

We also plot economic growth and satisfaction with economy by year and country (Appendix 6). Here, we observe that the changes in GDP growth correspond to changes in satisfaction with the economy across all countries. For visual purposes, presented in the article are the two most extreme years in the sample: 2006, the year before the crisis, and 2008, the sample year during the crisis. We notice that the drop in the growth rate between 2006 and 2008 coincides with a drop in satisfaction with the economy across the sample, with Ireland and Spain being the most extreme cases (both were severely hit by the negative effect of the crisis).

Second, we divide our sample depending on how the respondents voted. First, we take a subset of respondents who have voted for the governing party (Figure 2, upper left) and those who have cast a vote for opposition parties (Figure 2, upper right), to ascertain whether perceptions of the economy differ among both groups of voters. Subsequently, we divide the sample between those who voted for the party that had the prime ministerial position (Figure 2, lower left) and those who voted for all other parties that competed in the elections (Figure 2, lower right). We notice that among all four subsamples a similar pattern occurs, with a decline in the period of economic crisis, followed by a gradual recovery up to 2016 . The voting behaviour apparently does not make a difference with regard to these trends. What we can observe, however, is that those who voted for the governing party or the party of the prime minister have slightly higher scores in general, but fluctuations in the perceptions are very similar between both groups. As an example: there is a noticeable drop in economic perceptions between 2006 and 2008, which corresponds to the start of the global financial crisis. These fluctuations follow similar pattern over time (2002-2016), leading us to infer that both sets of voters perceive the economy similarly. Further, these initial 


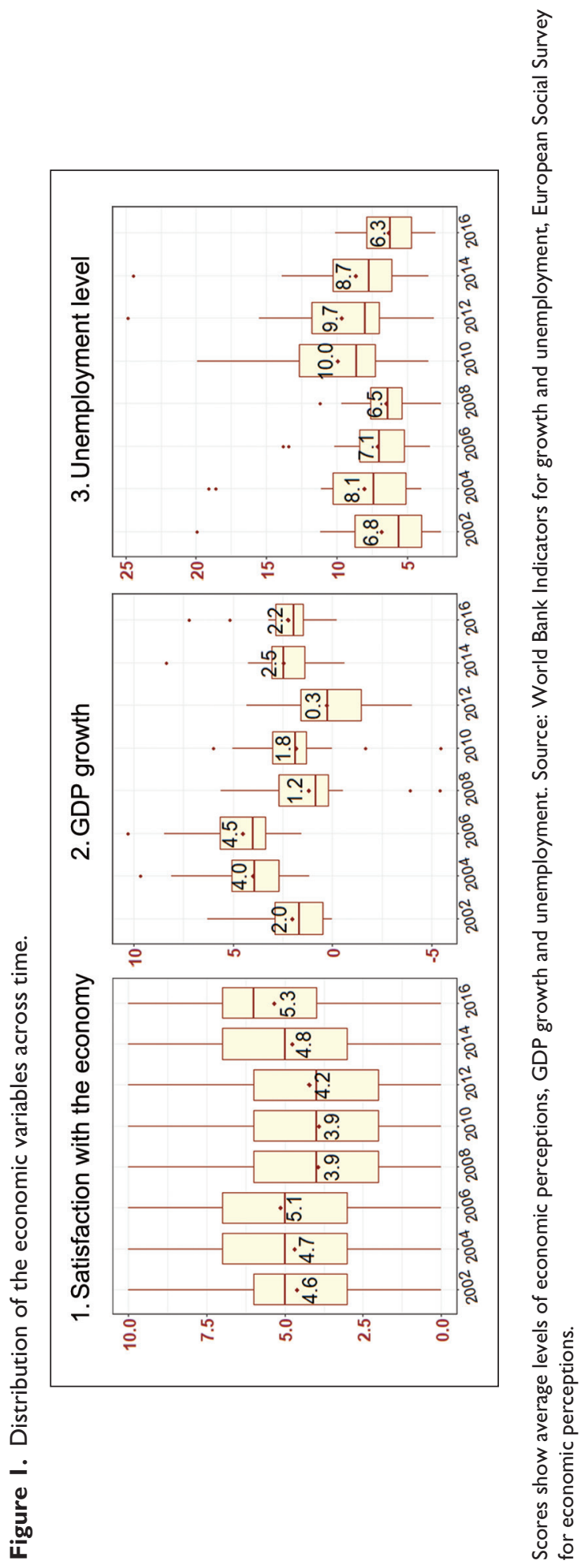


Figure Ia. Economic growth and satisfaction with economy across countries before the crisis in 2006 and during the crisis in 2008.

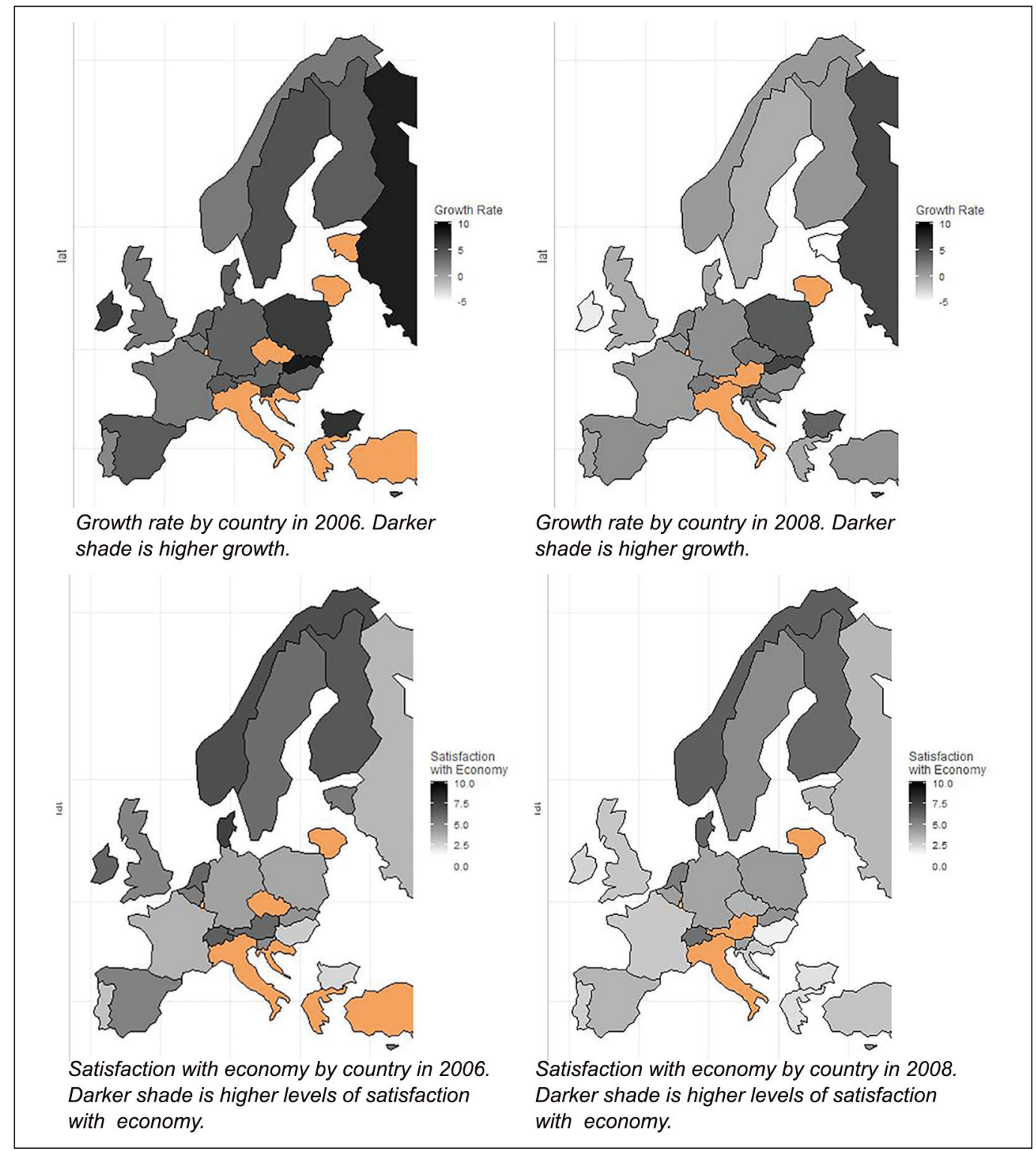

findings seem to suggest that voters' perceptions about the economy fluctuate in sync with reallife economic indicators (Sanders, 2000).

\section{Initial analysis}

Before we proceed with our full model analysis, we look at a more parsimonious model, where we only include our key variables of interest (Table 1). Entries result from a multilevel regression model, with satisfaction with the state of the economy as the dependent variable. In a first model, 
Figure 2. Satisfaction with the economy by vote choice.

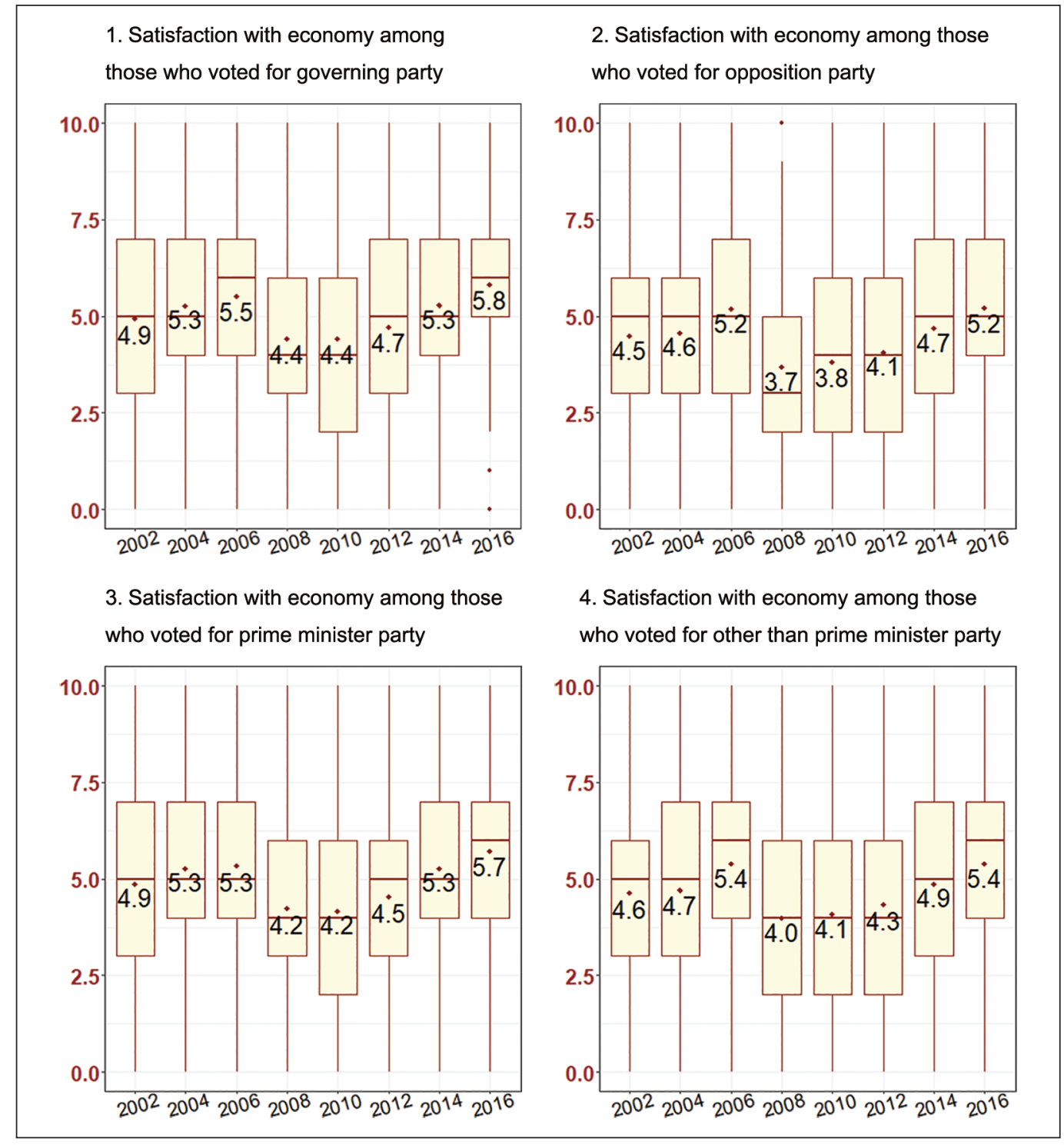

we only include the effect of GDP growth and the level of unemployment, and we observed that both variables are highly significant. This suggests that citizens indeed respond to changes in the real state of the economy in their country. While previous research only focused on endogeneity, these results suggest that, notwithstanding the presence of partisan bias, citizens do have an accurate view of the economy's performance. The results show that both GDP growth and unemployment level have a direct effect on satisfaction with the economy, so we do not have any reason to assume that one of these indicators would be more strongly preferred than the other. Whether we include having voted for the governing party (Model 2) or for the party of the prime minister (Model 3), it is highly relevant to note that these initial effects are not diminished. The idea that citizens respond to changes in the real economy is therefore supported by these results. 
Table I. Association between satisfaction with economy and real economic performance.

Dependent variable: Satisfaction with economy

(I)

(2)

(3)

\begin{tabular}{|c|c|c|c|}
\hline Gross domestic product growth & $\begin{array}{c}0.119^{* * *} \\
(0.034)\end{array}$ & $\begin{array}{c}0.120^{* * * * *} \\
(0.035)\end{array}$ & $\begin{array}{l}0.122^{\text {*** }} \\
(0.036)\end{array}$ \\
\hline Governing party & & $\begin{array}{l}0.343^{* * * k} \\
(0.023)\end{array}$ & \\
\hline Prime minister party & & & $\begin{array}{c}0.309^{\text {*** }} \\
(0.025)\end{array}$ \\
\hline Unemployment & $\begin{array}{l}-0.203^{* * * k} \\
(0.022)\end{array}$ & $\begin{array}{c}-0.212^{* * * *} \\
(0.022)\end{array}$ & $\begin{array}{c}-0.216^{\text {**** }} \\
(0.023)\end{array}$ \\
\hline Growth $\times$ Governing party & & $\begin{array}{l}0.012^{* *} \\
(0.004)\end{array}$ & \\
\hline Unemployment x Governing party & & $\begin{array}{l}0.019^{* * * *} \\
(0.002)\end{array}$ & \\
\hline Growth $x$ prime minister party & & & $\begin{array}{c}0.012^{* *} \\
(0.004)\end{array}$ \\
\hline Unemployment $\mathrm{x}$ prime minister party & & & $\begin{array}{l}0.023^{\text {**** }} \\
(0.003)\end{array}$ \\
\hline Constant & $\begin{array}{l}5.927^{* * *} \\
(0.217)\end{array}$ & $\begin{array}{l}5.77 I^{* * * *} \\
(0.220)\end{array}$ & $\begin{array}{l}5.882^{* * *} \\
(0.225)\end{array}$ \\
\hline $\begin{array}{l}\text { Random effects } \\
\text { Country/Year }\end{array}$ & $\begin{array}{c}1.295 \\
(1.138)\end{array}$ & $\begin{array}{c}1.328 \\
(1.152)\end{array}$ & $\begin{array}{c}1.384 \\
(1.177)\end{array}$ \\
\hline Residual & $\begin{array}{c}4.289 \\
(2.071)\end{array}$ & $\begin{array}{c}4.012 \\
(2.003)\end{array}$ & $\begin{array}{c}4.019 \\
(2.005)\end{array}$ \\
\hline Observations macro/micro & $178 / 329,089$ & $178 / 20 \mid, 126$ & $|78 / 20|, \mid 40$ \\
\hline Log likelihood & $-720,139.700$ & $-433,754.700$ & $-433,970.900$ \\
\hline AIC (Akaike Information Criterion) & $1,440,289.000$ & $867,525.400$ & $867,957.900$ \\
\hline BIC (Bayesian Information Criterion) & $\mathrm{I}, 440,343.000$ & $867,607.100$ & $868,039.500$ \\
\hline
\end{tabular}

Note: Entries are the result of a multilevel regression, European Social Survey 2002-2016.

$*_{p}<0.05 ; *_{p}<0.01 ; *^{* *} p<0.00 \mathrm{I}$. Standard error in parenthesis.

Our initial analysis points to a positive association between growth and satisfaction with the economy, as well as a negative association between unemployment and satisfaction with the economy (Model 1, Table 1). Consistency exists with the reported results in Model 2 and Model 3 , Table 1, where we interact real economic results (growth and unemployment) with vote choice, both for the governing party (Model 2) and for the prime minister party (Model 3). In both models, the association between growth and satisfaction with the economy is positive and statistically significant at the $0.1 \%$ level, while unemployment is negatively associated with our dependent variable (also significant at the $0.1 \%$ level). The interaction term in this parsimonious approach shows a positive effect between a vote for the governing party and satisfaction with the economy. However, the magnitude of this effect is fairly small. These findings indicate that those who voted for the governing party or the prime minister's party tend to be more satisfied with the economy on average; however, this difference seems not to be substantial in terms of its comparable effect size. Yet before coming to conclusions we need to investigate this relationship using models that control for a variety of possible intervening predictors. Most importantly, the 
effect of real-life economic indicators does not erode in our initial analysis, so it seems that respondents do have a rather accurate view of the state of the economy.

\section{Full models analysis}

To investigate our hypothesis more comprehensively, we turn to our full models, presented in Table 2, where Model 4 focuses on voting for a governing party, and Model 5 on voting for the party of the prime minister. In both models (Table 2), we include sets of covariates to take into consideration omitted variable bias. This allows us to distinguish the effect that other, not economic, factors might have on our models. We approach this modelling strategy by incorporating sets of standard controls in the economic voting model. First, we use demographic variables, such as gender, age and education of the respondents. ${ }^{10}$ Second, we employ standard political variables, such as left-right position and party identification to distinguish the economic effect from partisanship affiliation. This is very important as partisanship covariates are among the strongest predictors of vote choice. Our intention here is to see if economic perceptions follow economic trends or are purely a reflection of party affiliation. Thus, we would ideally like to isolate economic perceptions from partisanship in order to see if there are independent effects of the former. Finally, we control for a number of aggregate political system variables, such as the effective number of parties at the electoral level, effective number of parties at parliament level and the level of disproportionality of the political system. ${ }^{11}$ Partisanship might have a different effect in a two-party system compared to a multiparty system, therefore controlling for the disproportionality and the number of parties in the country is imperative.

We find that growth is positively associated with satisfaction with the economy, while unemployment has a negative impact on satisfaction with the economy in both Model 4 and Model 5 . The magnitude of this effect is fairly similar and significant $(p<0.001)$. However, our main research question is to investigate whether such an effect of real economic performance on satisfaction with the economy differs among various groups of voters, and this is done by including an interaction term. In both Model 4 and Model 5 of Table 2, the effects are similar, so we do not have any good argument to prefer having voted either for a governing party or for the party of the prime minister as the best indicator for support for the incumbent. The interaction effect provides us with information about how different sets of voters perceive changes in economic performance.

When considering the first interaction effect between GDP growth and vote choice, we find no evidence that the positive effect of growth has a different impact on satisfaction with the economy among different sets of voters. Voters tend to judge economic performance independently from their political preferences; that is, supporters of both governing parties and the opposition detect changes in real economic performance in a similar way. Although those who voted for the governing or prime ministerial party tend to be more satisfied with the economy on average $(\mathrm{H} 2)$, the slope remains quite similar between the two groups or does not differ significantly (H3). This leads us to believe that both groups of voters (governing or opposition) react similarly to positive or - for that matter - negative growth fluctuations.

Regarding unemployment, interaction effects are significant, indicating that different groups of voters tend to react differently to the level of unemployment. The interaction effect, however, does remain fairly small in size, as the coefficient size is about one-eighth larger for those who voted for the governing party or prime ministerial party compared to the others. Governing party supporters clearly react differently to the same level of unemployment as opposition supporters do. For visual purposes we plot the average estimated effect of growth and unemployment from our Model 4 and Model 5 in Figures 3 and 4. 
Table 2. Real economic performance and satisfaction with the economy.

Dependent variable: Satisfaction with economy

(4)

$0.159^{\text {**** }}$
$(0.032)$
$0.333^{\text {*** }}$
$(0.024)$

Prime minister party

Unemployment level

Growth $x$ governing party

Unemployment $\mathrm{x}$ governing party

Growth x prime minister party

Unemployment $\mathrm{x}$ prime minister party

Party identity

Left-right placement

Socio-demographic controls

Aggregate party system controls

Constant

Random effects

Country/Year

Residual

Observations macro/micro

Log likelihood

AIC (Akaike Information Criterion)

BIC (Bayesian Information Criterion)

0.004

$(0.004)$

$0.019^{* * * *}$

(0.002)

$0.136^{* * *}$

$(0.010)$

$0.101^{* * *}$

(0.002)

Yes

Yes

$3.002^{\text {*** }}$

(0.473)

0.9698

$(0.985)$

3.828

(1.956)

177//85,505

$790,896.100$

$791,058.200$
(5)

$0.159^{* * *}$

(0.032)

$0.322^{\text {**** }}$

(0.025)

$-0.156^{\text {*** }}$

(0.02I)

0.007

$(0.004)$

$0.020^{\text {**** }}$

$(0.003)$

$0.135^{* * * *}$

(0.010)

$0.103^{\text {*** }}$

(0.002)

Yes

Yes

$2.929^{* * *}$

(0.475)

0.979

(0.9896)

3.832

(1.958)

$177 / 185,518$

$-395,432.100$

$-395,570.900$

$791,173.800$

$791,335.900$

Note: Entries are the result of a multilevel regression, European Social Survey 2002-20I6.

$*_{p}<0.05 ; *_{p}<0.01 ; * * p<0.001$. Standard error in parenthesis. Full model presented in appendix (first table).

As expected, we observe that the differences in effect size based on vote choice are very small. However, since the interaction between unemployment levels and vote choice is statistically significant, we also plot the marginal effects by different values of both growth and unemployment, to see under which conditions this difference by vote occurs. Figure 5 shows the predicted probability of satisfaction with the economy for different levels of growth and unemployment among both sets of comparative models, those who voted for the governing party or the opposition (Figure 5) and those who voted for the prime ministerial party or another party (Figure 6). 
Figure 3. Estimated coefficients of growth and unemployment on satisfaction with the economy by respondents who voted for governing party or opposition.

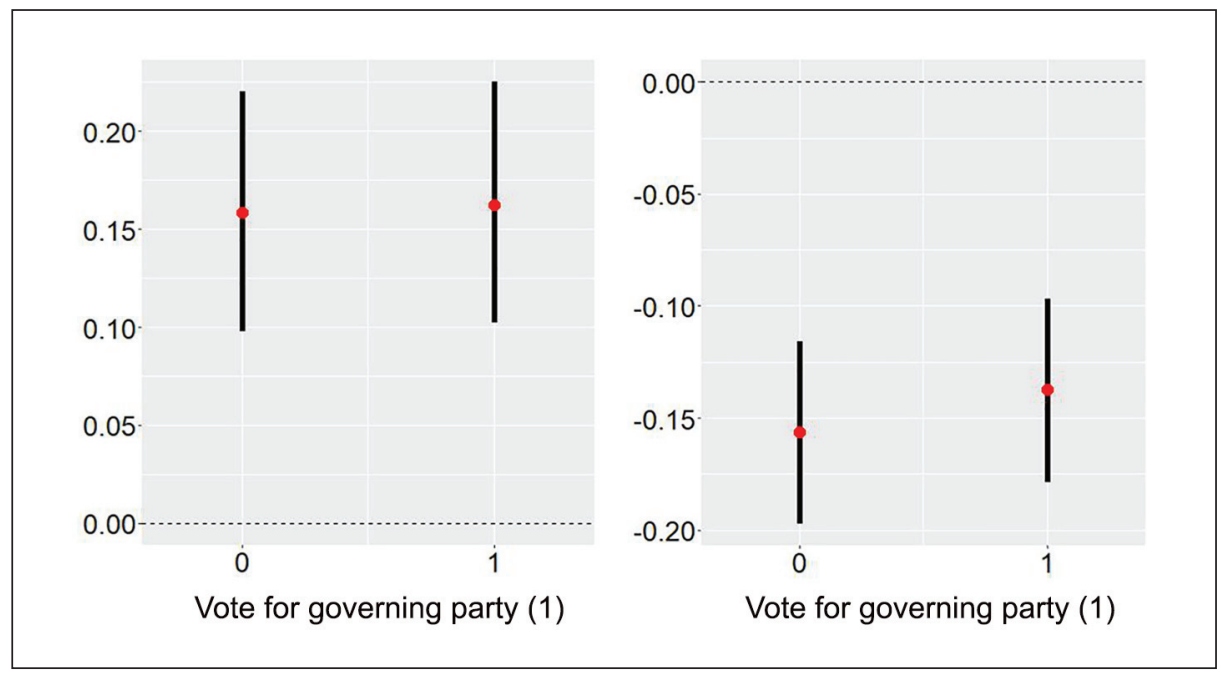

Figure 4. Estimated coefficients of growth and unemployment on satisfaction with the economy by respondents who voted for governing party or other party.

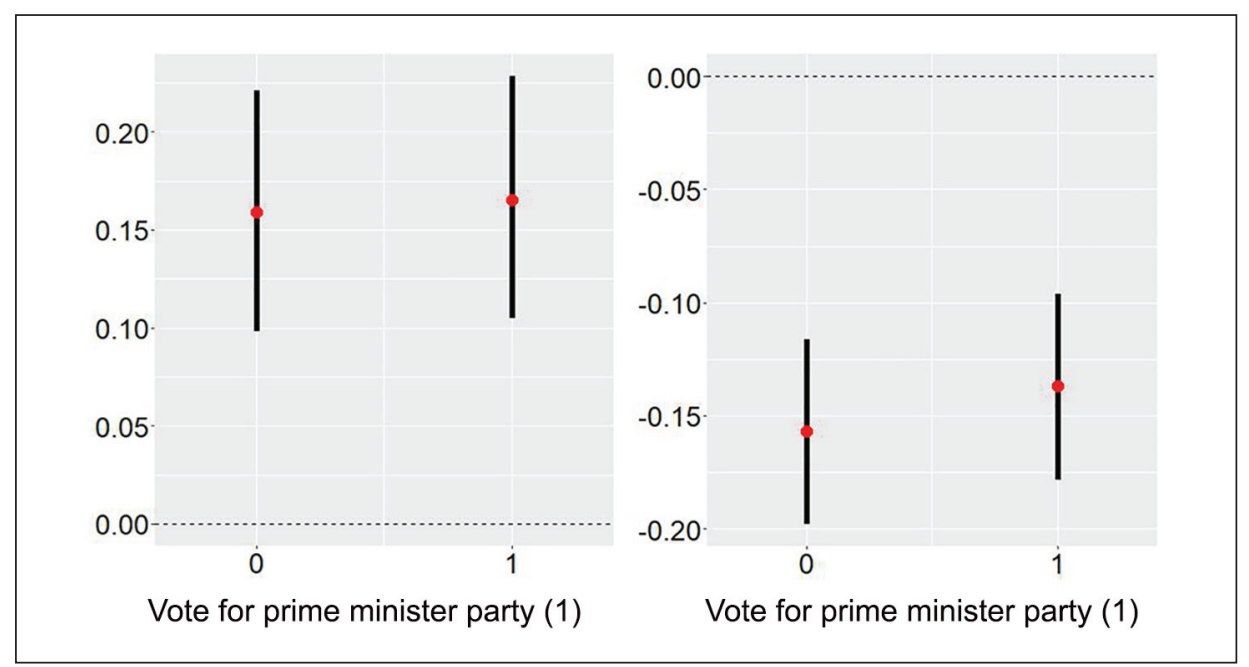

We gain two important findings from the marginal effect plots. First, the intercepts of the two groups are different. Those who voted for the governing party or the prime minister's party tend to have higher levels of satisfaction with the economy. These differences are around 0.5 on the scale of satisfaction with the economy. Those who voted for a governing party (Model 5) or the prime minister's party (Model 6) have, on average, about a half a percentage point higher responses on the satisfaction with the economy scale, compared to those who cast a vote for an opposition party (Model 5) or another party (Model 6). The confidence intervals and statistical significance corresponds, as expected, to the sample size with a significant difference between the two groups (those 
Figure 5. Marginal effects plot of growth and unemployment on satisfaction with the economy by respondents who voted for a governing party or opposition party by different levels of growth and unemployment.

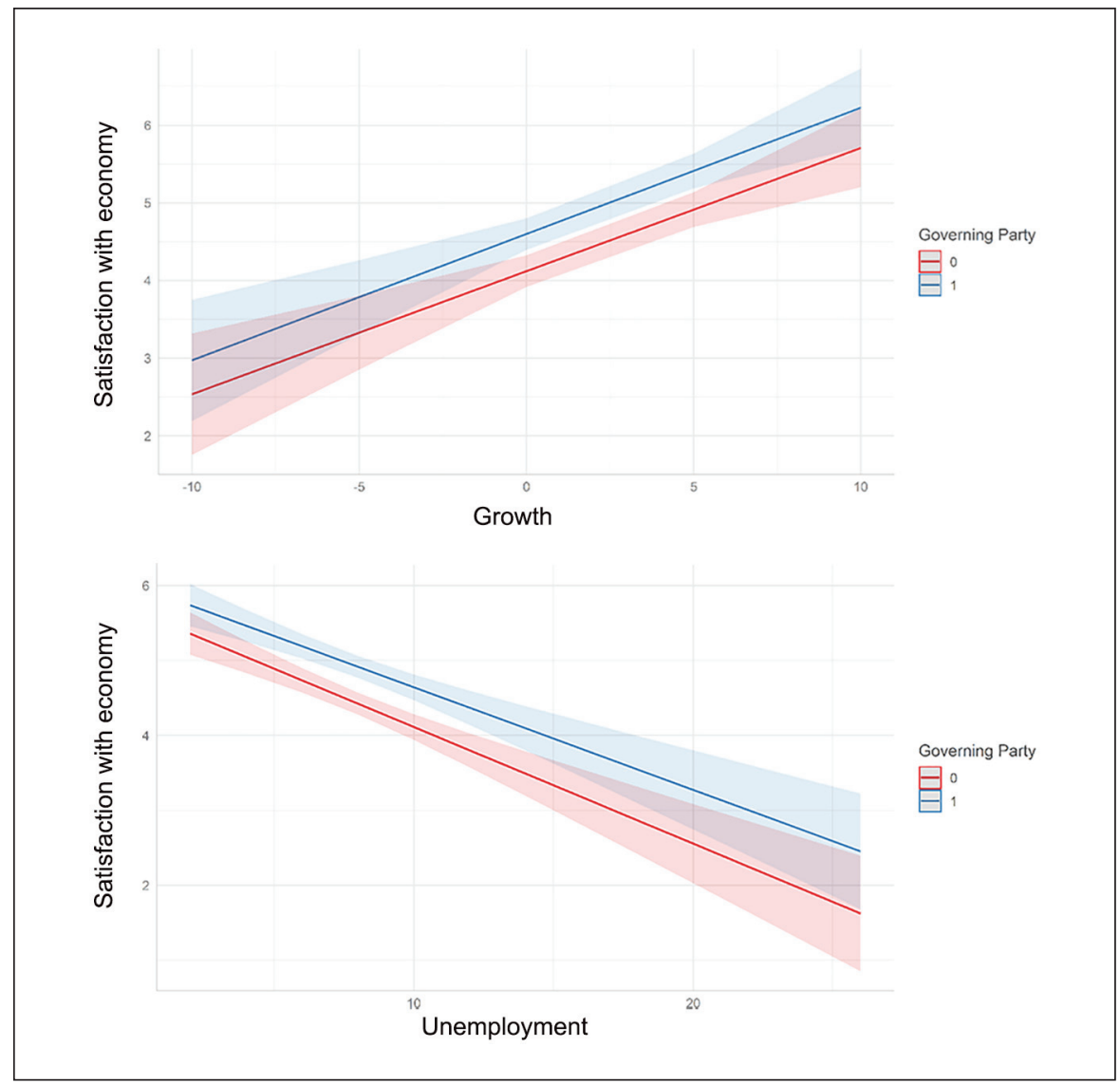

who voted for a governing party compared to an opposition party) as the number of observations increases (when GDP growth is between $0 \%$ and 5\% growth). ${ }^{12}$ Regarding unemployment, both Model 5 and Model 6 show a trend similar to that of GDP growth, with those who voted for the prime minister's party or the governing party reporting slightly higher scores on the satisfaction with the economy scale.

Second, in both Model 4 and Model 5 from Table 2 the slopes are almost parallel, indicating that both groups (governing party supporters and opposition supporters) shift their opinion based on real economic outcomes. Such inferences indicate that the real economic conditions have an independent effect on economic perceptions after all. In other words, both governing party or opposition supporters detect differences in economic performance across time and adjust their own economic perceptions accordingly. When the economy is growing, both groups perceive the economy as more positive, and when the economy shrinking this is also reflected in the satisfaction with the economy among all groups.

Finally, we also need to briefly discuss our findings regarding some of the covariates. At first glance, partisan preference seems to have a stronger effect on economic perception than GDP growth or unemployment, with coefficients more than twice the size of those for the real economy 
Figure 6. Marginal effects plot of growth and unemployment on satisfaction with the economy by respondents who voted for prime minister party or other party by different levels of growth and unemployment.

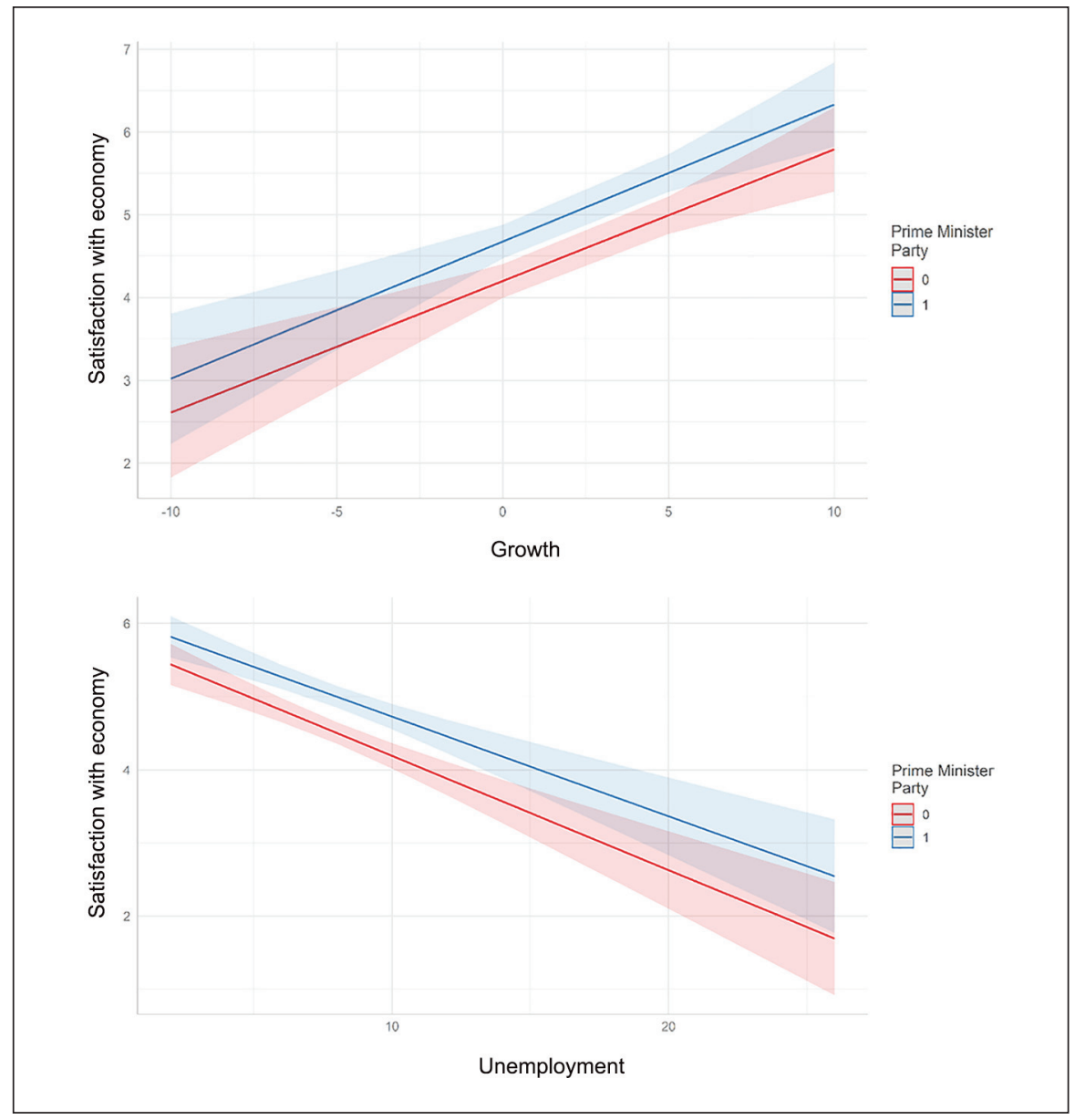

indicators. However, relying on such findings would bring issues regarding the direction of these coefficients, which is outside the scope of this study. In other words, is vote choice associated with the differences in satisfaction with economy or is it the other way around; is satisfaction with the economy associated with vote choice? Thus our investigation is to focus on the interaction effect between the real economic indicators and groups that cast a vote for the governing party or prime ministerial party compared to those who voted for the opposition. In our analysis, this direction is clear as it would be difficult to rationalize perceptions as predictors of real economic performance.

\section{Discussion}

Our first major finding is that we observe a strong association between economic indicators (both GDP growth and unemployment) and respondents' perceptions about the economy. Our results are therefore clearly in line with the conclusions of Sanders (2000) for the British case. Despite the ongoing debate on the validity of economic perceptions, we show that citizens 
indeed respond to economic changes in their country. To a large extent, this association between perceptions and real economic indicators can be found among government supporters as well as among opposition supporters. Even if we do find different levels of economic perceptions among the supporters of governing party/parties, compared to those who cast an opposition vote, this should not obliterate the fact that, by and large, citizens manage to get an accurate perception of the state of the economy.

Our results strongly suggest that in European countries, respondents' perceptions of the economy are in line with real economic performance, and this is something that characterizes all respondents regardless of their vote choice. Both governing party supporters and opposition supporters react positively to economic growth and decreasing unemployment and negatively when unemployment increases and growth decreases. This leads us to believe that economic perceptions vary similarly among different groups of partisans and that this variation is in line with real economic performance. Although biased responses based on partisanship emerge (especially with unemployment), we believe that these differences do not overrun the main effect that real economic performance has on economic perceptions.

Future research should determine the exact causal mechanism for explaining how citizens adjust their economic perceptions to changes in the real state of the economy. This could be based on the information they obtain from the mass media, or it could be based on the information they are exposed to in their own information interaction networks (Ansolabehere et al., 2014). In both cases, however, it can be assumed that voters have sufficient knowledge of real-life economic conditions in their country. In our analyses, GDP growth and unemployment levels had a roughly equal effect on levels of satisfaction. Although a level of partisan bias is present, citizens in general have a rather good perception of real-life economic indicators. The question to be answered is how exactly they obtain this information, and this is an important challenge for future research.

\section{Funding}

The authors received no financial support for the research, authorship and/or publication of this article.

\section{ORCID iD}

Martin Okolikj (iD https://orcid.org/0000-0002-8326-8576

\section{Supplemental material}

Supplemental material for this article is available online.

\section{Notes}

1. We use endogeneity in its statistical sense and bias in practical terms, but both capture a similar underlying concept.

2. Only Ukraine was excluded as the political and military instability in that country prevented reliable coding.

3. For robustness we also use changes in unemployment instead of levels of unemployment, and the results are reported in Appendix 4. We avoid using both growth and change in unemployment in our final models as the correlation is moderately high $(r=-0.48)$. The theoretical expectations presented in this paper, however, are in line with both types of modelling approach.

4. For Switzerland, we use the party which holds the foreign ministerial position. For France, the prime ministerial party corresponds to the party of the president.

5. We also use income as our control variable in Appendix 5. However, due to the large number of nonresponses we do not report income in our main models.

6. Full description of the variables is available in Appendix 1. 
7. As can be observed in Appendix 1, especially the variables: reported vote, left-right placement and party identification have a relatively large number of missing answers, resulting in a drop in the number of observations in our analysis.

8. We also run different model specifications with fixed effects for time and country. Second, we employ multiple linear regressions as a comparative model to the multilevel models presented in Table 2.

9. The interaction effect between growth and governing party in Model 4 in Appendix 8 and Appendix 10 is significant at the $5 \%$ level with a magnitude of the coefficient 0.01 . No significant variation is shown in Model 5.

10. We also use income as demographic control variable. However, due to the low level of responses, this is not included in the main analysis; see Appendix 5.

11. For a full description of the variables in our analysis, see Appendix 1.

12. We arrive at similar findings as the Parker-Stephen (2013) study. However, our reading of the results differs. We believe that the overlap of confidence intervals in extreme times might be due to the number of observations, rather than to different functions in extreme or ordinary periods.

\section{References}

Anderson, J Christopher (2007) The End of Economic Voting? Contingency dilemmas and the limits of democratic accountability. Annual Review of Political Science 10: 271-296.

Anderson, J Christopher, Silvia M Mendes and Yuliya V Tverdova (2004) Endogenous Economic Voting: Evidence from the 1997 British election. Electoral Studies 23(4): 683-708.

Ansolabehere, Stephen, Marc Meredith and Erik Snowberg (2014) Mecro-economic Voting: Local information and micro-perceptions of the macro-economy. Economics \& Politics 26(3): 380-410.

Borre, Ole (1997) Economic Voting in Danish Electoral Surveys 1987-94. Scandinavian Political Studies 20(4): 347-366.

Conover, Pamela Johnston, Stanley Feldman and Kathleen Knight (1986) Judging Inflation and Unemployment: The origins of retrospective evaluations. Journal of Politics 48(3): 565-588.

Dassonneville, Ruth and Marc Hooghe (2012) Election Forecasting Under Opaque Conditions: A model for Francophone Belgium, 1981-2010. International Journal of Forecasting 28(4): 777-788.

De Vries, Catherine, Sara B Hobolt and James Tilley (2018) Facing Up to the Facts: What causes economic perceptions? Electoral Studies 51: 115-122.

Duch, M Raymond, Harvey D Palmer and Christopher J Anderson (2000) Heterogeneity in Perceptions of National Economic Conditions. American Journal of Political Science 44(4): 635-652.

Evans, Geoffrey and Robert Andersen (2006) The Political Conditioning of Economic Perceptions. Journal of Politics 68(1): 194-207.

Evans, Geoffrey and Kat Chzhen (2016a) Re-evaluating the Valence Model of Political Choice. Political Science Research and Methods 4(1): 199-220.

Evans, Geoffrey and Kat Chzhen (2016b) Beyond Valence: Estimating models of party choice without resort to ecological fallacy or unfounded causal assumptions. A reply to Whiteley et al. Political Science Research and Methods 4(1): 241-247.

Evans, Geoffrey and Mark Pickup (2010) Reversing the Causal Arrow: The political conditioning of economic perceptions in the 2000-2004 US presidential election cycle. Journal of Politics 72(4): 1236-1251.

Gelman, Andrew and Jennifer Hill (2006) Data Analysis Using Regression and Multilevel/Hierarchical Models. Cambridge: Cambridge University Press.

Healy, Andrew and Gabriel S Lenz (2017) Presidential Voting and the Local Economy: Evidence from two population-based data sets. Journal of Politics 79(4): 1419-1432.

Hernández, Enrique and Hanspeter Kriesi (2016) The Electoral Consequences of the Financial and Economic Crisis in Europe. European Journal of Political Research 55(2): 203-224.

Hooghe, Marc and Jennifer Oser (2017) Partisan Strength, Political Trust and Generalized Trust in the United States: An analysis of the general social survey, 1972-2014. Social Science Research 68: 132-146.

Kramer, H Gerald (1971) Short-term Fluctuations in US Voting Behavior, 1896-1964. American Political Science Review 65(1): 131-143. 
Lewis-Beck, Michael and Mary Stegmaier (2000) Economic Determinants of Electoral Outcomes. Annual Review of Political Science 3: 183-219.

Lewis-Beck, Michael and Mary Stegmaier (2013) The VP-function revisited. Public Choice 157(3-4): 367-385.

Lewis-Beck, Michael and Richard Nadeau (2011) Economic Voting Theory: Testing new dimensions. Electoral studies 30(2): 288-294.

Lewis-Beck, Michael, Richard Nadeau and Angelo Elias (2008) Economics, Party, and the Vote: Causality issues and panel data. American Journal of Political Science 52(1): 84-95.

Lewis-Beck, Michael, Richard Nadeau and Martial Foucault (2013) The Compleat Economic Voter: New theory and British evidence. British Journal of Political Science 43(2): 241-261.

Nadeau, Richard and Michael Lewis-Beck (2001) National Economic Voting in US Presidential Elections. Journal of Politics 63(1): 159-181.

Nadeau, Richard, Michael S Lewis-Beck and Éric Bélanger (2013) Economics and Elections Revisited. Comparative Political Studies 46(5): 551-573.

Okolikj, Martin and Stephen Quinlan (2016) Context Matters: Economic voting in the 2009 and 2014 European parliament elections. Politics and Governance 4(1): 145-166.

Paldam, Martin and Peter Nannestad (2000) What Do Voters Know About the Economy?: A study of Danish data, 1990-1993. Electoral Studies 19(2-3): 363-391.

Parker-Stephen, Evan (2013) Tides of Disagreement: How reality facilitates (and inhibits) partisan public opinion. Journal of Politics 75(4): 1077-1088.

Powell, G Bingham Jr and Guy D Whitten (1993) A Cross-national Analysis of Economic Voting: Taking account of the political context. American Journal of Political Science 37(2): 391-414.

Sanders, David (2000) The Real Economy and the Perceived Economy in Popularity Functions: How much do voters need to know?: A study of British data, 1974-97. Electoral Studies 19(2-3): 275-294.

Stevenson, Randolph T and Raymond Duch (2013) The Meaning and Use of Subjective Perceptions in Studies of Economic Voting. Electoral Studies 32(2): 305-320.

Van der Brug, Wouter, Cees Van der Eijk and Mark Franklin (2007) The Economy and the Vote: Economic Conditions and Elections in Fifteen Countries. Cambridge: Cambridge University Press.

Whiteley, Paul and Ann-Kristin Kölln (2019) How Do Different Sources of Partisanship Influence Government Accountability in Europe? International Political Science Review 40(4): 502-517.

Whiteley, Paul, Harold Clarke, David Sanders, et al. (2016) Hunting the Snark: A reply to 'Re-evaluating valence models of political choice'. Political Science Research and Methods 4(1): 221-240.

Wilcox, Nathaniel and Christopher Wlezien (1993) The Contamination of Responses to Survey Items: Economic perceptions and political judgments. Political Analysis 5: 181-213.

Zaller, John R (1992) The Nature and Origins of Mass Opinion. Cambridge: Cambridge University Press.

\section{Author biographies}

Martin Okolikj is a postdoctoral researcher at the Centre for Political Research at KU Leuven, Belgium, working on the 2019 Belgian Election Study. His research interests are comparative electoral behaviour, democratization and political methodology.

Marc Hooghe is a professor of political science at the University of Leuven (Belgium). He has published extensively on social capital, political participation and political socialization. An ongoing topic in his research is the way political participation patterns change over time, especially among younger age groups, and what effect these trends have on the quality of representative democracy. 